\title{
Memory Consolidation for Contextual and Auditory Fear Conditioning Is Dependent on Protein Synthesis, PKA, and MAP Kinase
} \author{
and Joseph E. LeDoux ${ }^{1}$ \\ W.M. Keck Foundation Laboratory of Neurobiology \\ Center for Neural Science \\ New York University \\ New York, New York 10003 USA
}

Glenn E. Schafe, Nicole V. Nadel, Gregory M. Sullivan, Alexander Harris,

\begin{abstract}
Fear conditioning has received extensive experimental attention. However, little is known about the molecular mechanisms that underlie fear memory consolidation. Previous studies have shown that long-term potentiation (LTP) exists in pathways known to be relevant to fear conditioning and that fear conditioning modifies neural processing in these pathways in a manner similar to LTP induction. The present experiments examined whether inhibition of protein synthesis, PKA, and MAP kinase activity, treatments that block LTP, also interfere with the consolidation of fear conditioning. Rats were injected intraventricularly with Anisomycin (100 or $300 \mu \mathrm{g}$ ), Rp-cAMPS (90 or $180 \mu \mathrm{g}$ ), or PD098059 ( 1 or $3 \mu \mathrm{g}$ ) prior to conditioning and assessed for retention of contextual and auditory fear memory both within an hour and $24 \mathrm{hr}$ later. Results indicated that injection of these compounds selectively interfered with long-term memory for contextual and auditory fear, while leaving short-term memory intact. Additional control groups indicated that this effect was likely due to impaired memory consolidation rather than to nonspecific effects of the drugs on fear expression. Results suggest that fear conditioning and
\end{abstract}

${ }^{1}$ Corresponding author.
LTP may share common molecular mechanisms.

\section{Introduction}

Classically conditioned fear is a behavioral paradigm in which animals learn to fear an initially neutral stimulus (CS; conditioned stimulus) that has been paired or followed by presentation of a noxious unconditioned stimulus (US), such as foot shock (Bouton and Bolles 1980; Davis 1992; LeDoux 1992). The learning is rapid and is extremely robust and enduring (LeDoux et al. 1989), characteristics that make fear conditioning well suited for the study of the neural mechanisms of learning and memory in the mammalian brain.

Whereas the neuroanatomical pathways and synaptic events underlying conditioned fear have been well characterized (see, e.g., Davis 1992; LeDoux 1992, 1995; Maren and Fanselow 1996), relatively little is known about the molecular mechanisms that underlie fear memory. In contrast, considerable progress has been made in elucidating the molecular changes underlying longterm potentiation (LTP), the leading cellular model of memory consolidation in the mammalian brain (see, e.g., Alberini et al. 1995; Kandel 1997; Milner et al. 1998). It is thus of interest that LTP has been demonstrated in pathways known to be relevant to fear conditioning (Chapman et al. 1990; Clugnet and LeDoux 1990; Rogan and LeDoux 1995; Rogan et al. 1997; Huang and Kandel 1998). Further, neural activity in the brain is modified similarly during fear conditioning and LTP induction (Rogan et al.

LEARNING \& MEMORY 6:97-110 @ 1999 by Cold Spring Harbor Laboratory Press ISSN1072-0502/99 \$5.00

$$
\begin{array}{lllllllllllllll}
L & E & A & R & N & I & N & G & \begin{array}{l}
\boldsymbol{Q} \\
97
\end{array} & M & E & M & O & R & Y
\end{array}
$$


1997; McKernan and Shinnick-Gallagher 1997). Collectively, these results suggest that LTP and fear memory consolidation may share common molecular mechanisms.

Several forms of LTP have been extensively characterized using both in vitro brain slice preparations and in vivo preparations, especially in the hippocampus (see, e.g., Bliss and Lømo 1973; Madison et al. 1991; Barnes et al. 1995). Although the synaptic and molecular events underlying the induction of these various forms of LTP appear to differ (Madison et al. 1991), each has recently been shown to be characterized by two distinct temporal phases. The "early" phase (E-LTP), lasting from 1 to $3 \mathrm{hr}$, appears to involve covalent modification of existing proteins and does not require protein or RNA synthesis (Frey et al. 1993; Huang et al. 1994; Nguyen and Kandel 1996). The "late" phase (LLTP), lasting from hours to days, is dependent upon de novo RNA and protein synthesis and appears to involve both the cAMP-dependent (PKA) and mitogen-activated (MAP) protein kinase signaling pathways (Frey et al. 1993; Huang et al. 1994; Nguyen and Kandel 1996; English and Sweatt 1997; Atkins et al. 1998; Impey et al. 1998a). These intracellular signaling pathways are thought to transduce the activity-dependent changes characteristic of shorter forms of synaptic plasticity into long-term structural and functional change by engaging activators of transcription in the nucleus (Alberini et al. 1995; Kandel 1997; Milner et al. 1998a). In support of this hypothesis, application of RNA or protein synthesis inhibitors or selective inhibitors of PKA to hippocampal slices prior to tetanization of the perforant or Schaffer collateral pathways has been shown to prevent the induction of L-LTP, while having no effect on that of E-LTP (Frey et al. 1993; Huang et al. 1994; Nguyen and Kandel 1996). Similarly, application of inhibitors to MAP kinase has been shown to prevent the induction of L-LTP in the Schaffer collateral pathway (English and Sweatt 1997; Atkins et al. 1998; Impey et al. 1998), while having little effect on E-LTP (Impey et al. 1998). Finally, stimuli that generate L-LTP in hippocampus have been shown to induce the transcription of cAMP response element (CRE)-mediated genes, an effect that is prevented by inhibitors of PKA or MAP kinase (MAPK) (Impey et al. 1996, 1998a). Collectively, results suggest that signal transduction involving both PKA and MAPK are necessary for the long-term protein synthesis-dependent synaptic plasticity believed to underlie memory consolidation (see, e.g., Kandel 1997;
Kornhauser and Greenberg 1997, Abel et al. 1998; Milner et al. 1998).

The following experiments are part of a series of investigations we are conducting in an attempt to define the role of protein synthesis and intracellular signaling pathways in the acquisition and retention of classically conditioned fear to auditory and contextual stimuli. Although significant progress has been made in implicating specific circuits in fear conditioning (Davis 1992; LeDoux 1992, 1995; Maren and Fanselow 1997), in this initial study we have chosen to target these circuits broadly using intraventricular injections of drugs. Specifically, rats were injected intraventricularly with Anisomycin (a protein synthesis inhibitor), Rp-cAMPS (a PKA inhibitor), or PD098059 (a MAPK inhibitor) prior to conditioning and tested for fear memory retention both within $1 \mathrm{hr}$ (shortterm memory, STM) and $24 \mathrm{hr}$ later (long-term memory, LTM). Each of these compounds has been shown in previous studies to impair L-LTP, while having little effect on E-LTP (Huang et al. 1994; Nguyen and Kandel 1996; English and Sweatt 1997; Impey et al. 1998). Consistent with the LTP literature, our results indicate that administration of these compounds dose dependently disrupted long-term, but not short-term, memory for fear. Additional control groups determined that this effect was specific to memory and not secondary to effects of the drugs on normal behavioral expression. Collectively, results suggest that fear memory consolidation and LTP may involve similar molecular mechanisms.

\section{Materials and Methods}

SUBJECTS

Subjects were adult male Sprague-Dawley rats obtained from Hilltop Labs, Scottdale, PA. Rats were housed individually in plastic Nalgene cages and maintained on a 12:12 hr light/dark cycle. Food and water were provided ad libitum throughout the experiment.

\section{SURGERY}

Under Nembutal anesthesia ( $45 \mathrm{mg} / \mathrm{kg}$ ), rats were implanted unilaterally with a 26-gauge stainless steel cannula into the left lateral ventricle. Coordinates, taken from Paxinos and Watson (1986) and adjusted according to pilot data, were $0.4 \mathrm{~mm}$ posterior to bregma, $1.3 \mathrm{~mm}$ lateral to the midline,

$$
\begin{array}{lllllllllllllll}
L & E & A & R & N & I & N & G & \begin{array}{l}
\boldsymbol{\bigotimes} \\
98
\end{array} & M & E & M & O & R & Y
\end{array}
$$


and $4.2 \mathrm{~mm}$ ventral to the skull surface. The cannula was anchored to the skull with stainless steel screws and a mixture of acrylic and dental cement. A 33-gauge dummy cannula was inserted to prevent clogging. Following surgery, rats were given $0.2 \mathrm{mg} / \mathrm{kg}$ buprenorphine $\mathrm{HCl}$ as an analgesic. Rats were given at least 4 days to recover prior to experimental procedures.

\section{DRUGS}

Rats were injected with either Anisomycin (Sigma, cat. no. A9789), Rp-adenosine 3',5'-cyclic monophosphothioate triethylamine (Rp-cAMPS; RBI, cat. no. A-165), or PD098059 (RBI, cat. no. P-215). Anisomycin was dissolved in equimolar $\mathrm{HCl}$, diluted with artificial cerebrospinal fluid (ACSF), and adjusted to $\mathrm{pH} 7.4$ with $\mathrm{NaOH}$. RpcAMPS was dissolved in ACSF. PD098059 was dissolved in $100 \%$ DMSO. Anisomycin is a potent inhibitor of mRNA translation via interference with transpeptidation and has been used successfully in a number of behavioral paradigms (see, e.g., Davis and Squire 1984). Rp-cAMPS inhibits the activation of cAMP-dependent protein kinases I and II by cAMP (Rothermel and Parker-Botelho 1988). PD098059 is a specific inhibitor of the activation of MAPK kinase (MEK), an upstream regulator of MAPK (Alessi et al. 1995).

\section{INTRAVENTRICULAR INJECTIONS}

For drug injections, rats were held gently in the experimenter's lap. The dummy cannula was removed and replaced with a 33-gauge injector cannula attached to a $5.0 \mu$ l Hamilton syringe via 20-gauge polyurethane tubing. The tubing was back-filled with sesame oil to provide adequate pressure for drug injection. A small air bubble separated the oil from the drug solution. Drugs were infused slowly via infusion pump into the lateral ventricle at a rate of $0.25 \mu \mathrm{l} / \mathrm{min}$. Following drug infusion, cannulas were left in place for an additional minute to allow diffusion of the drug away from the cannula tip. Dummy cannulas were then replaced and the rat was returned to its home cage.

\section{APPARATUS}

Conditioning and tone testing were conducted in two distinct chambers. For conditioning, rats were placed in a Plexiglas rodent conditioning chamber (chamber A) with a metal grid floor (Model E10-10, Coulbourn Instruments, Lehigh Valley, PA) that was enclosed within a sound attenuating chamber (model E10-20). The chamber was dimly illuminated by a single house light. For tone testing, rats were placed in a distinct Plexiglas chamber to minimize generalization from the conditioning environment (ENV-001, MedAssociates, Inc., Georgia, VT). The tone testing chamber (chamber B) was brightly lit with three house lights and contained a flat black formica floor that had been washed with a peppermint soap. A microvideo camera was mounted at the top of the chamber so that rats could be videotaped during testing.

\section{HISTOLOGY}

To verify the location of the cannula tip within the lateral ventricle, rats were anesthetized with an overdose of chloral hydrate $(250 \mathrm{mg} / \mathrm{kg}$; i.p.) and injected manually with $5.0 \mu \mathrm{l}$ of a $0.5 \%$ solution of Cresyl violet into the ventricle. Rats were then decapitated and brains were removed and postfixed in $10 \%$ buffered formalin in $30 \%$ sucrose. Brains were then cut into 5-mm blocks and examined for dye in the ventricles. Blocks containing the cannula track were then sectioned on a cryostat at 50 $\mu \mathrm{m}$ thickness and stained for Nissl using Thionine. Sections were examined with light microscopy for cannula penetration into the lateral ventricle.

\section{GENERAL BEHAVIORAL PROCEDURES}

HABITUATION AND CONDITIONING

Figure 1 outlines the general behavioral procedures used in each experiment. On the day prior to conditioning (day 1), rats were habituated for 15 min to chambers A and B. On the conditioning day (day 2), separate groups of rats were injected with either Anisomycin (100 or $300 \mu \mathrm{g} ; 5 \mu \mathrm{l})$, Rp-cAMPS (90 or $180 \mu \mathrm{g} ; 5 \mu \mathrm{l}$ ), PD098059 (1 or $3 \mu \mathrm{g} ; 3 \mu \mathrm{l}$ ), or an equivalent volume of vehicle (ACSF; DMSO) 30 min prior to conditioning. The doses of Anisomycin were chosen based on recently published data showing that i.c.v. administration of $200 \mu \mathrm{g}$ in the rat inhibits protein synthesis in the hippocampus by $>90 \%$ within $20 \mathrm{~min}$ of injection (Meiri and Rosenblum 1998). Doses of Rp-cAMPS and PD098059 were chosen based on their effectiveness at blocking fear memory in pilot experiments.

$$
\begin{array}{llllllllllllllll} 
& E & A & R & N & I & N & G & \begin{array}{l}
\boldsymbol{Q} \\
9
\end{array} & M & E & M & O & R & Y
\end{array}
$$




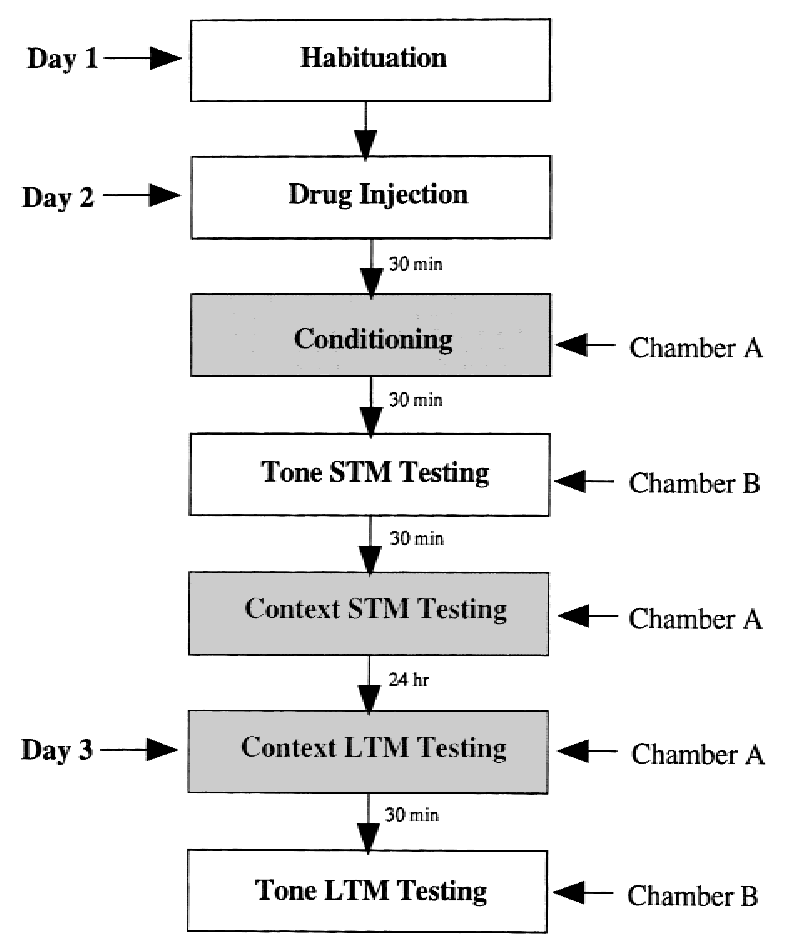

Figure 1: Outline of general behavioral procedures.

Following a 5 min acclimation period to the conditioning chamber, paired rats received a single conditioning trial consisting of a 30-sec presentation of a $5-\mathrm{kHz}, 70-\mathrm{dB}$ tone (CS) that coterminated with a $1.5-\mathrm{mA}$ foot shock (US) delivered through the grid floor during the last $1.0 \mathrm{sec}$ of the tone. Unpaired controls were injected with vehicle (ACSF; DMSO) and also received tones and shocks, but in a noncontingent, explicitly unpaired fashion. For these groups, the US shock preceded the CS tone $(5 \mathrm{kHz}, 70 \mathrm{~dB}, 30 \mathrm{sec})$ by $60 \mathrm{sec}$. Following conditioning, all rats were returned to their home cages.

SHORT-TERM MEMORY TESTING

STM to the tone was evaluated $30 \mathrm{~min}$ after conditioning. For this test, rats were placed in chamber $\mathrm{B}$ and given 2 exposures to the CS tone (30 sec, $5 \mathrm{kHz}, 70 \mathrm{~dB}$ ) with an average intertrial interval (ITI) of $100 \mathrm{sec}$. Rats were videotaped during CS presentations for subsequent quantification of behavior. Time spent "freezing" during the presentation of the tone CS was measured during each CS presentation as well as during a 30-sec baseline period prior to the first tone trial (see, e.g., Bouton and Bolles 1980; LeDoux et al. 1990a for details).
This latter measure served as an assay for both unconditioned effects of the drugs on general activity levels and for fear generalization between the conditioning and tone-testing chambers. Following tone testing, rats were returned to their home cages. To evaluate STM to the context, rats were again placed in the conditioning chamber (chamber A) 30 min following the tone test (for a total of 60 min following conditioning). Rats were allowed to explore for $5 \mathrm{~min}$, after which freezing to the context was assessed every other $30 \mathrm{sec}$ for an additional $5 \mathrm{~min}$ (for a total of five 30-sec observations).

LONG-TERM MEMORY TESTING

LTM for both the context and the tone were evaluated the following day (day $3 ; \sim 24 \mathrm{hr}$ following conditioning). For the context test, rats were placed in chamber A and allowed to explore for 5 min, after which freezing to the context was assessed every other $30 \mathrm{sec}$ for an additional $5 \mathrm{~min}$. For the tone test, rats were again placed in chamber $\mathrm{B}$ and presented with 5 tones $(30 \mathrm{sec}, 5 \mathrm{kHz}, 70$ $\mathrm{dB}$, ITI = $100 \mathrm{sec}$ ). As for STM testing, freezing was evaluated during each presentation of the tone CS and during the 30-sec baseline period prior to the first tone trial. Following the memory tests, rats were returned to their home cages and to the colony.

RECONDITIONING

To evaluate whether the injection of these compounds resulted in long-term inability to express fear or to associate tones and shocks, rats were reconditioned drug free $\sim 1$ week after LTM testing. As before, rats received a single pairing of a $30-\mathrm{sec}, 5-\mathrm{kHz}, 70-\mathrm{dB}$ tone that coterminated with a 1-sec $1.5-\mathrm{mA}$ foot shock. Twenty-four hours later, rats were evaluated for long-term contextual and auditory fear memory as described above.

\section{Results and Discussion}

INTRAVENTRICULAR INJECTION OF ANISOMYCIN, Rp-cAMPS, AND PD098059 DOSE-DEPENDENTLY IMPAIRED THE CONSOLIDATION OF CONTEXTUAL AND AUDITORY FEAR MEMORY

Histological observations revealed that most rats had successful cannula placements in the lateral ventricle. Only those rats with observable dye in the ventricle were included in the data analysis. 


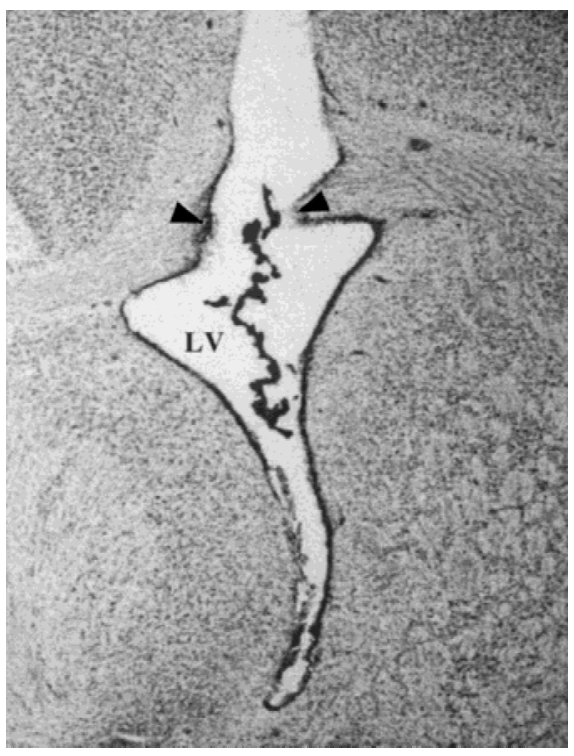

Figure 2: Representative cannula placement in the lateral ventricle (LV). (Arrows) Point of entry. Cresyl violet dye can be seen lining the ventricle ependyma.
A photograph of a representative cannula placement in the lateral ventricle can be found in Figure 2 .

Figures 3, 4, and 5 depict mean percent freezing for contextual (A) and auditory (C) fear memory for rats injected with Anisomycin, RpcAMPS, PD098059, or vehicle. Baseline levels of freezing prior to the first trial in the tone memory tests (STM, LTM) can be found in B. The top and middle panels in each figure represent absolute scores for STM and LTM trials, respectively. The bottom panels represent mean percent LTM. For this latter score, LTM scores for both context and tone were averaged for each rat. All data were analyzed using analysis of variance (ANOVA) and Duncan's multiple range $t$-tests.

\section{ANISOMYCIN}

Relative to ACSF-injected controls, rats injected with either dose of Anisomycin displayed intact fear to the context when tested $60 \mathrm{~min}$ after
A
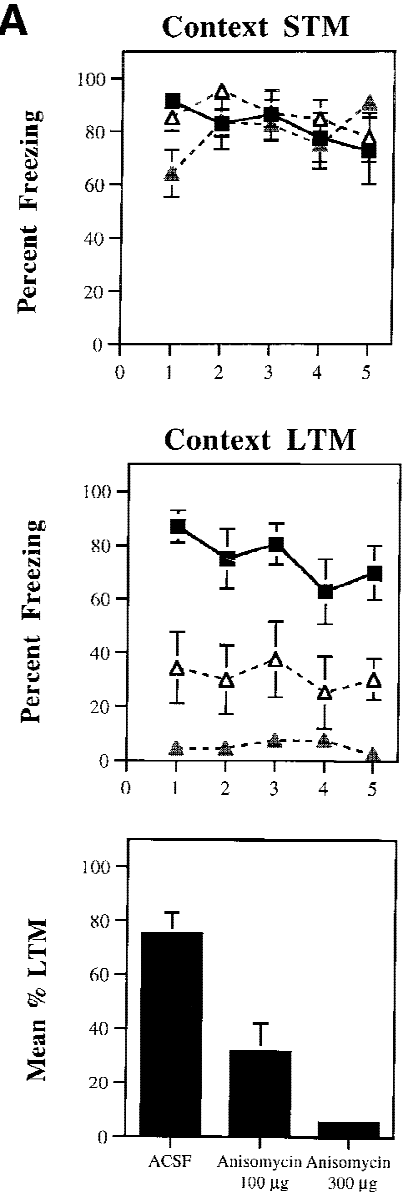

B
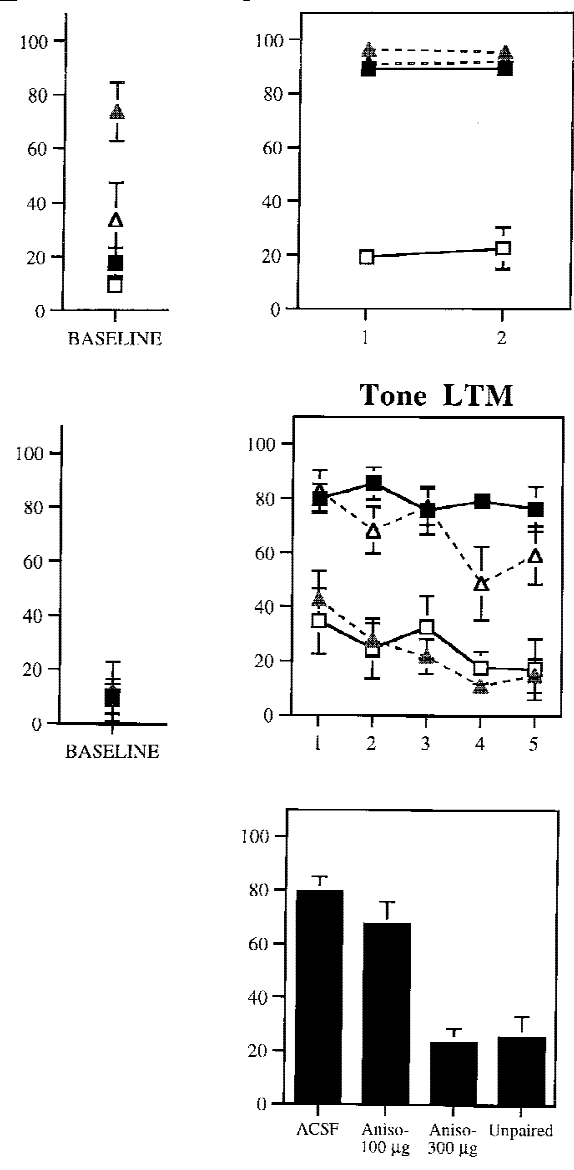

Figure 3: (A) (Top) Mean ( \pm S.E.) percent freezing for context STM in rats injected with ACSF $(\mathbf{\square} ; n=10), 300 \mu \mathrm{g}$ Anisomycin (shaded triangles; $n=9$ ), or $100 \mu \mathrm{g}$ Anisomycin $(\triangle ; n=7)$. (Middle) Mean $( \pm$ S.E.) freezing for context LTM in the same rats. (Bottom) Mean ( \pm S.E.) percent context LTM for ACSF- and Anisomycininjected rats. (B) (Top) Mean ( \pm S.E.) percent freezing during the baseline period prior to the first trial in the STM tone test. (Middle) Mean ( \pm S.E.) percent freezing during the baseline period prior to the first trial in the LTM tone test $(C)(T o p)$ Mean $( \pm$ S.E.) percent freezing for tone STM in unpaired controls $(\square ; n=8)$, and rats injected with ACSF (匚), $300 \mu \mathrm{g}$ Anisomycin (shaded triangles), or $100 \mu \mathrm{g}$ Anisomycin $(\triangle)$. (Middle) Mean $( \pm$ S.E.) freezing for tone LTM in the same rats. (Bottom) Mean ( \pm S.E.) percent tone LTM for ACSF- and Anisomycin-injected rats, and unpaired controls.

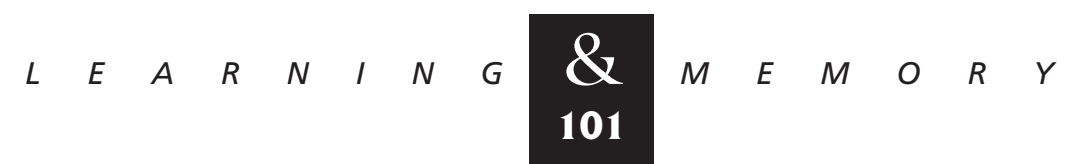




\section{Schafe et al.}

Figure 4: (A) (Top) Mean ( \pm S.E.) percent freezing for context STM in rats injected with ACSF $(\boldsymbol{\square} ; n=9), 180 \mu \mathrm{g}$ Rp-CAMPS (shaded triangles; $n=7$ ), or $90 \mu \mathrm{g}$ RpcAMPS $(\triangle ; n=8)$. (Middle) Mean ( \pm S.E.) freezing for context LTM in the same rats. (Bottom) Mean ( \pm S.E.) percent context LTM for ACSF- and Rp-CAMPS-injected rats. (B) (Top) Mean ( \pm S.E.) percent freezing during the baseline period prior to the first trial in the STM tone test. (Middle) Mean ( \pm S.E.) percent freezing during the baseline period prior to the first trial in the LTM tone test. (C) (Top) Mean ( \pm S.E.) percent freezing for tone STM in rats injected with ACSF $(\boldsymbol{\square}), 180 \mu \mathrm{g}$ Rp-CAMPS (shaded triangles), or $90 \mu \mathrm{g}$ Rp-cAMPS $(\triangle)$. (Middle) Mean ( \pm S.E.) freezing for tone LTM in the same rats. (Bottom) Mean ( \pm S.E.) percent tone LTM for ACSF- and Rp-cAMPS-injected rats.

A
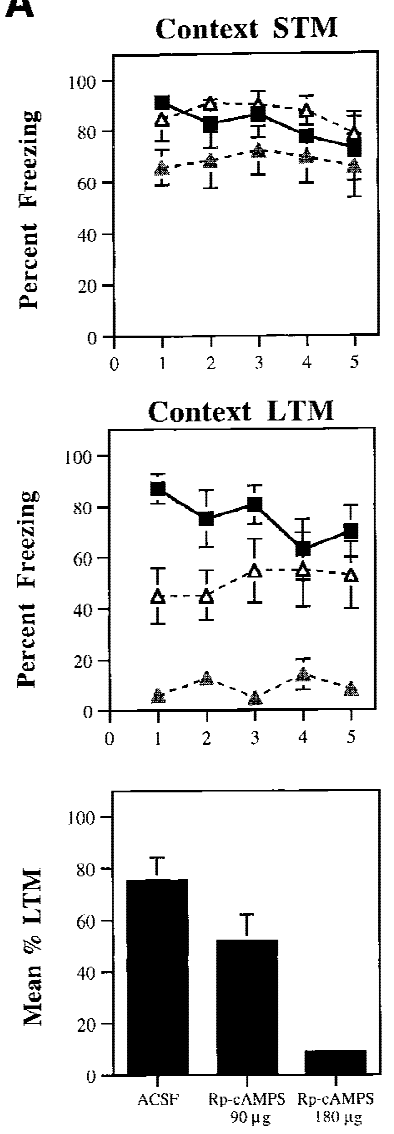

B
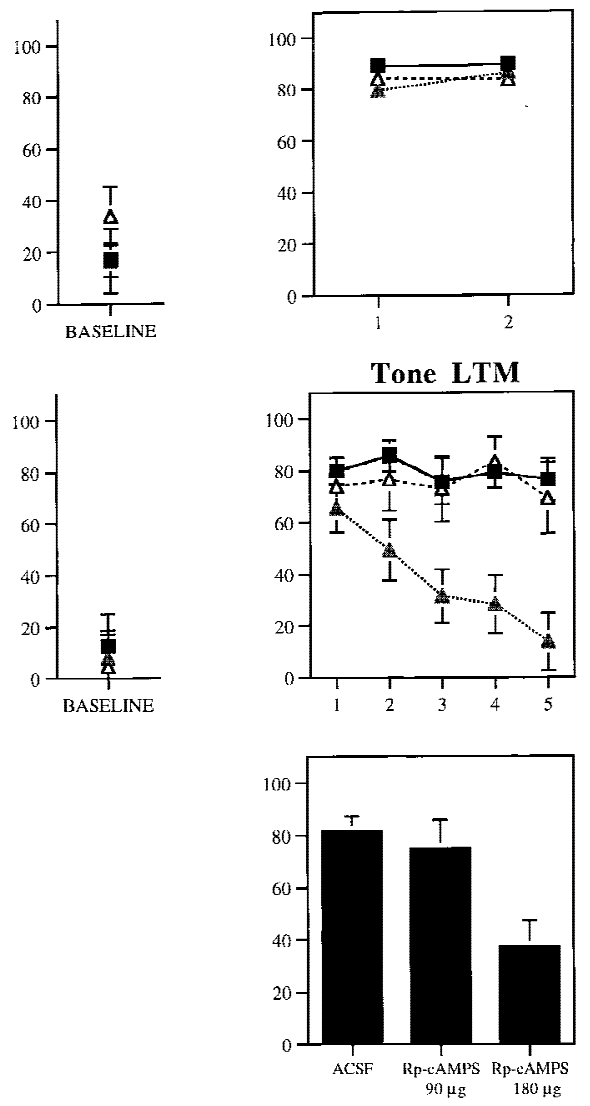

conditioning (Fig. 3A). The ANOVA for context STM scores revealed no differences $(P>0.05)$. Twenty-four hours later, however, both Anisomycin groups showed substantial memory impairment. The ANOVA (group by trials) for context LTM scores showed a significant effect for group (ACSF vs. $100 \mu \mathrm{g}$ vs. $300 \mu \mathrm{g}),[F(2,23)=26.49$, $P<0.01]$. The effect for trials and the interaction did not achieve significance $(P>0.05)$. Post-hoc $t$-tests revealed that freezing scores for both Anisomycin groups differed from the ACSF group on every trial $(P<0.05)$. In contrast, the high-dose group differed from the low-dose group only on trials one and four $(P<0.05)$. This same pattern of results is reflected in the mean context LTM scores $[F(2,23)=26.49, P<0.01]$, where memory impairment following either dose of Anisomycin was found to differ from the ACSF group $(P<0.05)$. The two drug groups were also found to differ $(P<0.05)$.

The results for tone memory showed a similar pattern (Fig. 3C). The ANOVA for tone STM scores revealed a significant effect for group (ACSF vs.
$100 \mu \mathrm{g}$ vs. $300 \mu \mathrm{g}$ vs. unpaired) $[F(3,29)=90.66$, $P<0.01$ ], a nonsignificant effect for trials, and a nonsignificant group by trials interaction. Both drug groups showed strong, intact STM for the tone, and they were not found to differ on either trial from each other or from the ACSF group $(P>0.05)$. Both drug groups and ACSF controls, however, were found to differ significantly from the unpaired group on each tone trial $(P<0.05)$, indicating that STM to the tone was associative.

Twenty-four hours later, however, rats injected with the highest dose of Anisomycin (300 $\mu \mathrm{g})$ showed little fear retention. The ANOVA for tone LTM scores revealed a significant effect for group $[F(3,29)=20.20, P<0.01]$, a significant effect for trials $[F(4,116)=8.69, P<0.01]$, and a nonsignificant group by trials interaction. Post-hoc $t$-tests revealed that the high-dose group differed from both ACSF controls and the low-dose group on every trial $(P<0.05)$. In fact, LTM scores for this group did not differ significantly from those of unpaired rats at any point $(P>0.05)$. In contrast, the low-dose group was found to differ from ACSF

$$
\begin{array}{lllllllllllllll}
\hline & E & A & R & N & I & N & G & \begin{array}{c}
\boldsymbol{Z} \\
102
\end{array} & M & E & M & O & R & Y
\end{array}
$$


FEAR MEMORY CONSOLIDATION

A
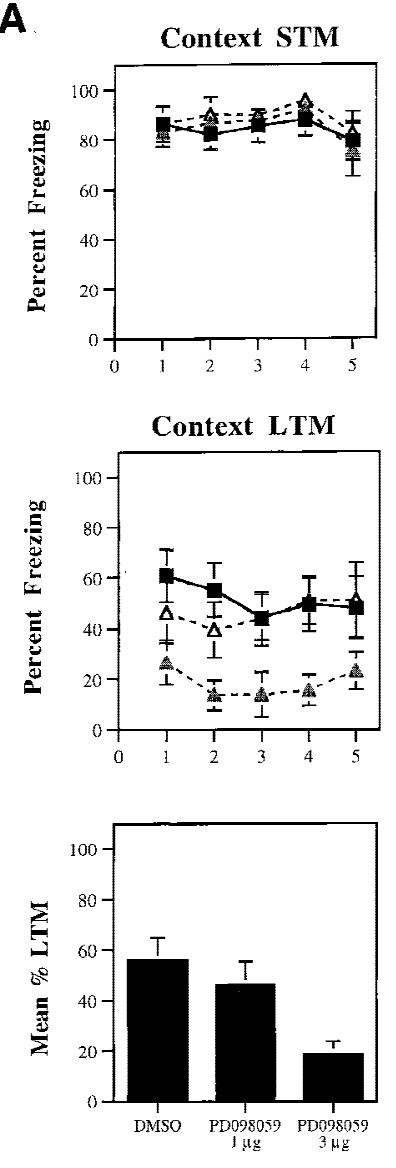

B
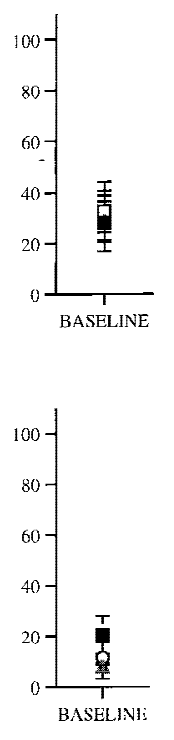

controls only on the fourth tone trial $(P<0.05)$. This same pattern of results is reflected in the mean LTM scores $[F(3,29)=20.20, P<0.01]$, where memory impairment following the high dose of Anisomycin was found to differ from the other two groups $(P<0.05)$. Overall, no significant difference was detected between the ACSF and the low-dose group. Additionally, no difference was detected between the unpaired group and the group receiving the highest dose of Anisomycin.

Although tone STM scores for rats injected with the high dose of Anisomycin were not found to differ from those of the other groups on either trial, it should be noted that baseline levels of freezing for this group were found to be significantly higher than the other groups (Fig. 3B; $P<0.05$ ). At this dose $(300 \mu \mathrm{g})$, Anisomycin apparently produced either motor deficits or a general state of malaise characterized by general inactivity. These observations are in keeping with previous reports of the toxicity of protein synthesis inhibitors, including reports of suppressed activity within $1 \mathrm{hr}$
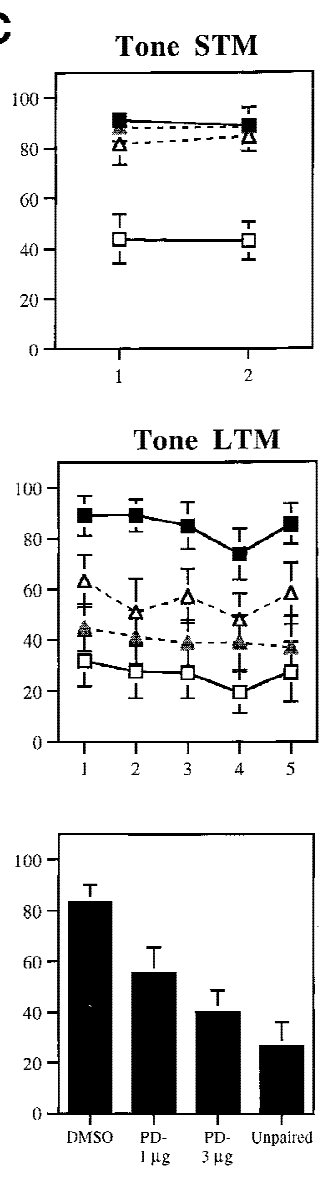

Figure 5: (A) (Top) Mean ( \pm S.E.) percent freezing for context STM in rats injected with DMSO $(\boldsymbol{\square} ; n=11), 3 \mu \mathrm{g}$ PD098059 (shaded triangles; $n=9$ ), or $1 \mu \mathrm{g}$ PD098059 $(\triangle ; n=8)$. (Middle) Mean $( \pm$ S.E.) freezing for context LTM in the same rats. (Bottom) Mean ( \pm S.E.) percent context LTM for DMSO- and PD098059injected rats. (B) (Top) Mean ( \pm S.E.) percent freezing during the baseline period prior to the first trial in the STM tone test. (Middle) Mean ( \pm S.E.) percent freezing during the baseline period prior to the first tone trial in the LTM tone test. $(C)$ (Top) Mean ( \pm S.E.) percent freezing for tone STM in unpaired rats $(\square ; n=8)$, and rats injected with DMSO (ם), $3 \mu \mathrm{g}$ PD098059 (shaded triangles), or $1 \mu \mathrm{g}$ PD098059 ( $\triangle$ ). (Middle) Mean ( \pm S.E.) freezing for tone LTM in the same rats. (Bottom) Mean ( \pm S.E.) percent tone LTM for DMSO- and PD098059-injected rats and unpaired controls. following treatment with a high systemic dose (150 mg/kg) of Anisomycin (Davis and Squire 1984). However, although the behavioral inactivity in the high-dose group complicates the interpretation of the STM results for both context and tone, rats in this group nonetheless displayed significantly more freezing to both STM tone presentations than in the baseline period $(P<0.05)$. This suggests that they did in fact have intact STM for the tone. Further, baseline freezing scores in the low-dose group were not different from those in ACSF or unpaired controls $(P>0.05)$, despite substantial memory impairment for the low dose in the context LTM test. It thus appears likely that the pronounced LTM deficits seen in the high-dose group for both context and tone may be attributed to memory impairment rather than to unconditioned effects of the drug.

Rp-cAMPS

The pattern of results for Rp-cAMPS was similar to those for Anisomycin (Fig. 4A). Relative to

$$
\begin{array}{lllllllllllllll}
L & E & A & R & N & I & N & G & \boldsymbol{\bigotimes} \\
103 & M & E & M & O & R & Y
\end{array}
$$


ACSF-injected controls, rats injected with either dose of Rp-cAMPS displayed intact context STM on each trial $(P>0.05)$. Twenty-four hours later, however, rats receiving the highest dose $(180 \mu \mathrm{g})$ showed little contextual fear, and those injected with the low dose $(90 \mu \mathrm{g})$ showed attenuated fear relative to ACSF controls. The ANOVA (group by trials) for context LTM scores showed a significant effect for group (ACSF vs. $90 \mu \mathrm{g}$ vs. $180 \mu \mathrm{g}$ ) $[F(2$, $21)=16.15, P<0.01]$, a nonsignificant effect for trials $(P>0.05)$, and a significant group by trials interaction $[F(8,84)=2.21, P<0.05]$. Post hoc $t$ tests revealed that this latter effect was due to differences between ACSF controls and the low-dose group in the first two trials. No differences were detected between these two groups in the last three trials. Importantly, freezing scores in rats receiving the highest dose of Rp-cAMPS (180 $\mu \mathrm{g})$ were found to be different from the other two groups on every trial. This same pattern of results is evident in the mean context LTM scores $[F(2$, $21)=16.15, P<0.01]$, where memory impairment following the $180 \mu \mathrm{g}$ dose of Rp-cAMPS was found to differ from that of the other groups $(P<0.05)$. Overall, no significant differences were detected between the ACSF and $90 \mu \mathrm{g}$ groups, although a clear trend was noted $(P=0.05)$.

Rp-cAMPS had no effect on tone STM (Fig. 4C). The ANOVA for tone STM scores revealed no significant effects $(P>0.05)$. Additionally, no differences were detected between groups for the baseline period $(P>0.05)$ (Fig. 4B). Twenty-four hours later, however, rats injected with the highest dose of Rp-cAMPS showed deficits in LTM for the tone. The ANOVA for tone LTM scores revealed a significant effect for group $[F(2,21)=6.94, P<0.01]$, a significant effect for trials $[F(4,84)=7.77$, $P<0.01]$, and a significant group by trials interaction $[F(8,84)=4.94, P<0.01]$. Post hoc $t$-tests revealed that there were no differences between groups for either the baseline period or for the first tone trial. However, rats injected with the high dose of Rp-cAMPS were found to differ from ACSF controls on trials $2-5(P<0.05)$ and from the group injected with the lower dose of Rp-cAMPS on trials 3-5 $(P<0.05)$. No differences were detected between ACSF controls and rats injected with the low dose of Rp-cAMPS on any trial. This same pattern of results is reflected in the mean tone LTM scores $[F(2,21)=6.94, P<0.01]$, where memory impairment following the high dose of Rp-cAMPS was found to differ from the other two groups $(P<0.05)$. Overall, no significant differ- ences were detected between the ACSF and lowdose groups.

Although we did not run unpaired controls associated with the rats injected with Rp-cAMPS, the overall tone LTM for the high-dose group was found to be about $40 \%$ of STM, which is not significantly different from that found for rats injected with the highest dose of Anisomycin $(P>0.05)$. Additionally, it can be seen in Figure $4 \mathrm{C}$ that rats injected with the highest dose of Rp-cAMPS had equivalent freezing scores to vehicle controls on the first tone trial. Thus, it appears that some memory to the tone remained intact following treatment with this dose. We were not able to examine the effects of higher doses, however, as doses above $200 \mu \mathrm{g}$ produced seizures in pilot experiments.

PD098059

Context STM memory for rats injected with either dose of PD098059 was not found to differ from that of DMSO controls $(P>0.05)$ (Fig. 5A). Twenty-four hours later, however, rats injected with the highest dose of PD098059 showed evidence of memory impairment. The ANOVA for context LTM scores showed a significant effect for group (DMSO vs. $1 \mu \mathrm{g}$ vs. $3 \mu \mathrm{g}$ ), $[F(2,25)=5.86$, $P<0.01$ ], a nonsignificant effect for trials, and a nonsignificant interaction. Freezing scores for rats injected with the highest dose of PD098059 were found to be different from DMSO controls on all but the fifth trial. No differences were detected on any trial between DMSO controls and the low-dose group. This same pattern of results is evident in the mean context LTM scores $[F(2,25)=5.86$, $P<0.01]$, where the high-dose group was found to differ from both DMSO controls and the low-dose group $(P<0.05)$. No difference was detected between DMSO controls and the low-dose group.

As before, tone STM was intact for all groups relative to unpaired controls (Fig. 5C). The ANOVA for tone STM scores revealed a significant effect for group (DMSO vs. $1 \mu \mathrm{g}$ vs. $3 \mu \mathrm{g}$ vs. unpaired) $[F(3$, $32)=13.35, P<0.01]$, a nonsignificant effect for trials, and a nonsignificant group by trials interaction. Additionally, no differences between groups were detected for the baseline period (Fig. 5B). Post-hoc $t$-tests revealed no differences between DMSO controls and PD098059-injected groups for either tone trial $(P>0.05)$. The unpaired group, however, was found to be different from the other groups on both trials $(P<0.05)$, indicating that

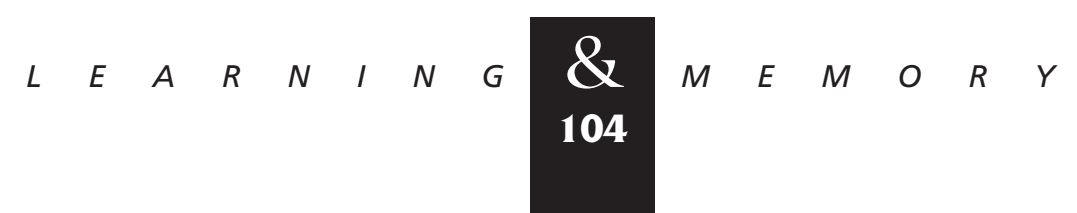


freezing to the tone shortly after conditioning was associative.

As with the other drugs, rats injected with PD098059 showed impaired tone memory when tested $24 \mathrm{hr}$ later, and this effect was most pronounced for the highest dose of the drug. The ANOVA for tone LTM scores revealed a significant effect for group $[F(3,32)=8.65, P<0.01]$, a nonsignificant effect for trials, and a nonsignificant group by trials interaction. Additionally, no differences in freezing scores existed between groups for the baseline period. However, post-hoc tests revealed that both unpaired controls and rats injected with the highest dose of PD098059 differed from DMSO controls on every tone trial. No differences were detected between the two doses of PD098059, or between these doses and the unpaired group $(P>0.05)$. This same pattern of results was seen in the mean tone LTM scores $[F(3$, $32)=8.65, \quad P<0.01]$, where both doses of PD098059 were shown to produce memory impairment relative to DMSO $(P<0.05)$. Overall, no significant difference was detected between the two doses of PD098059.

INJECTION OF ANISOMYCIN, Rp-cAMPS, OR PD098059 DID NOT PREVENT NORMAL ACQUISITION TO THE CONTEXT OR TONE FOLLOWING RECONDITIONING 1 WEEK LATER

Figure 6A depicts mean percent freezing to the context and tone following reconditioning. It is evident in the figure that rats in each group were able to reacquire and express fear to both cues. An ANOVA for both context and tone memory revealed no effects $(P>0.05)$. Thus, the memory impairment produced by these compounds appears to be transient ( $<1$ week), and the drugs do not appear to result in permanent inability to express fear or to associate tones and shocks.

INJECTION OF ANISOMYCIN, Rp-cAMPS, OR PD098059 24 HR PRIOR TO CONDITIONING HAS NO EFFECT ON FEAR ACQUISITION OR EXPRESSION

In the previous experiments, rats were injected with Anisomycin, Rp-cAMPS, or PD098059 $30 \mathrm{~min}$ prior to conditioning and tested for LTM approximately $24 \mathrm{hr}$ later. Although each of these groups displayed intact STM and was able to be reconditioned approximately 1 week later, the pos-
A

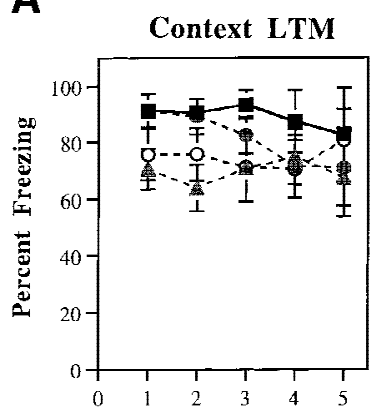

B

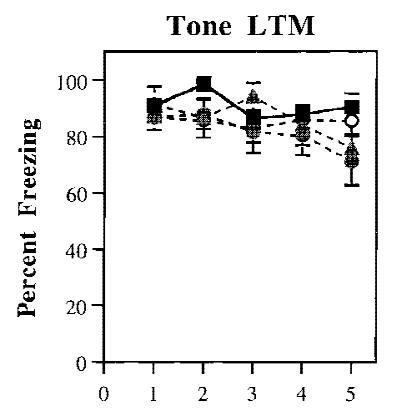

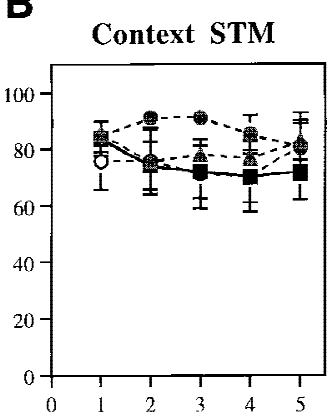

Tone STM

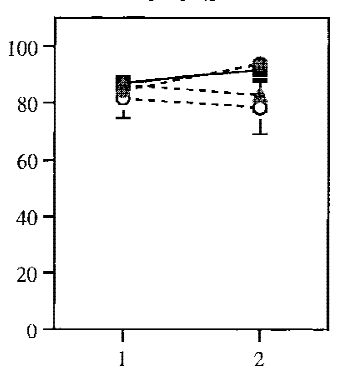

Figure 6: (A) Mean ( \pm S.E.) percent freezing for context (top) and tone (bottom) LTM following re-conditioning in rats injected with ACSF (ם), $300 \mu$ g Anisomycin (shaded triangles), $180 \mu \mathrm{g}$ Rp-cAMPS (shaded circles), or $3 \mu \mathrm{g}$ PD098059 (○). Rats were tested for context and tone memory $24 \mathrm{hr}$ after reconditioning. (B) Mean ( \pm S.E.) percent freezing for context (top) and tone (bottom) STM in rats injected with ACSF $(\boldsymbol{\square} ; n=8), 300 \mu \mathrm{g}$ Anisomycin (shaded triangles; $n=8$ ), $180 \mu \mathrm{g}$ Rp-cAMPS (shaded circles; $n=8)$, or $3 \mu \mathrm{g}$ PD098059 $(\bigcirc ; n=8) 24 \mathrm{hr}$ prior to conditioning. Rats were evaluated for tone and context memory either 30 or 60 min following conditioning, respectively.

sibility remains that the failure to display significant amounts of freezing on test day represents a nonspecific effect of the drugs on normal behavioral expression $24 \mathrm{hr}$ following injection. To evaluate this possibility, additional groups of rats were injected with the highest doses of Anisomycin $(300 \mu \mathrm{g})$, Rp-cAMPS (180 $\mu \mathrm{g}$ ), or PD098059 (3 $\mu \mathrm{g}) 24 \mathrm{hr}$ prior to conditioning. The following day, rats were conditioned and tested for STM as described above. Thus, each group was subjected to STM tests for fear at approximately the same time as rats in the previous experiments were subjected to LTM tests. Freezing scores for each group can found in Figure 6B. It is evident in the figure that rats in each group displayed normal amounts of freezing behavior to both the context and tone and that no differences existed between groups. An ANOVA confirmed this $(P>0.05)$. Thus, it is un-

$$
\begin{array}{lllllllllllllll}
L & E & A & R & N & I & N & G & \boldsymbol{Q} \\
105 & M & E & M & O & R & Y
\end{array}
$$


likely that the memory deficits seen in rats injected with these compounds $30 \mathrm{~min}$ prior to conditioning are due to nonspecific effects of the drugs on behavioral expression $24 \mathrm{hr}$ after injection.

\section{General Discussion}

Previous studies have shown that LTP exists in pathways known to be relevant to fear conditioning and that fear conditioning modifies neural activity in these pathways in the same manner that LTP does (Chapman et al. 1990; Clugnet and LeDoux 1990; Rogan and LeDoux 1995; Rogan et al. 1997; Huang and Kandel 1998; McKernan and Shinnick-Gallagher 1997). These studies suggest that fear conditioning and LTP may share similar molecular mechanisms. The present experiments examined whether pharmacological inhibition of protein synthesis, PKA, and MAPK activity, treatments that block LTP, also interfere with memory consolidation for fear conditioning. Results indicated that interference with these pathways selectively and dose dependently interfered with LTM for contextual and auditory fear, while leaving STM intact. This pattern of selective interference with LTM is similar to that observed in the LTP literature in which interference with these pathways has been shown to block L-LTP, while having little effect on E-LTP (Frey et al. 1993; Huang et al. 1994; Nguyen and Kandel 1996; Impey et al. 1998a). Collectively, results favor the conclusion that fear memory consolidation and LTP share common molecular mechanisms.

The present results are in agreement with recent reports showing that pharmacological inhibition of protein synthesis and PKA in mice blocks consolidation of contextual fear memory (Bourtchouladze et al. 1998) and that systemic inhibition of the MAPK signaling pathway blocks both contextual and auditory fear in rats (Atkins et al. 1998). The former study, however, did not evaluate fear memory to the tone, and the latter did not evaluate STM to either the tone or the context. In contrast to these previous reports, the present studies evaluated both STM and LTM to both context and tone. Additionally, we provide three sets of evidence that indicate that the behavioral effects of Anisomycin, Rp-cAMPS, and PD098059 are likely to be the result of impaired memory consolidation rather than a nonspecific effect on fear acquisition or expression. First, rats injected with these compounds displayed intact and comparable STM relative to vehicle-injected controls to both the con- text and the tone shortly after conditioning. Thus, rats were able to perceive the tone, form a representation of the context, and acquire normal fear to each stimulus when paired with foot shock while under the influence of the drugs. Second, rats were able to be reconditioned 1 week later and to reacquire normal fear to both the context and the tone, indicating that injection of these compounds did not result in permanent inability of the rats to express fear or associate tones and shocks. Third, rats were able to acquire and express normal amounts of fear to both the tone and the context when injected with these compounds $24 \mathrm{hr}$ prior to conditioning and STM testing, indicating that the memory impairment observed during the LTM tests was not due to nonspecific effects on fear expression on the day after injection. When considered together with other recent reports (Atkins 1998; Bourtchouladze et al. 1998), our results strongly favor the conclusion that both the cAMP and MAPK signaling pathways are necessary for the long-term protein-synthesis dependent changes underlying fear memory consolidation.

Because rats in our experiments were injected prior to conditioning and thus trained under the influence of drugs, it might be argued that the effects that we observed on LTM were the result of state-dependent learning rather than impaired memory consolidation. We believe, however, that this is an unlikely possibility. First, a recent paper by Kandel and colleagues employing administration of Anisomycin and Rp-cAMPS in mice found equivalent effects on contextual fear memory with both pre- and immediate post-training injections (Bourtchouladze et al. 1998). Second, Atkins et al. (1998) found that both pre- and immediate posttraining systemic administration of SL327, a MEK inhibitor similar functionally to PD098059, impairs memory consolidation of contextual and auditory fear. Because impaired memory was demonstrated following both pre- and post-training administration of each of these compounds, it cannot be concluded that memory impairment on the day following conditioning is due to state-dependent learning. Indeed, an effect of these compounds on memory following post-training administration adds further evidence to the argument that they are exerting their effects on memory consolidation rather than on sensory processing or some other nonspecific factor.

Studies utilizing invertebrate and in vitro cell culture preparations have provided a number of suggestions regarding the mechanisms whereby

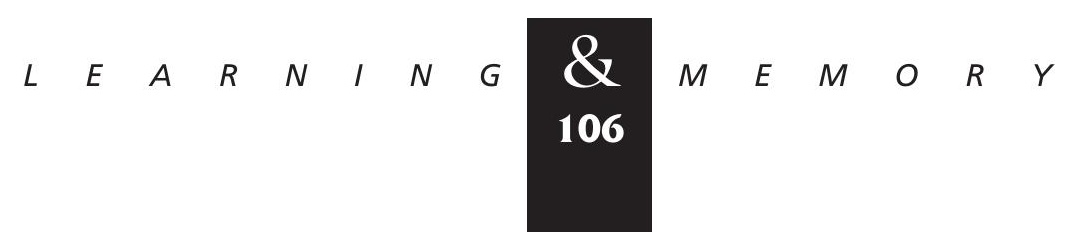


the cAMP and MAPK signaling pathways promote long-term synaptic plasticity. In Aplysia, for example, facilitation of the gill-withdrawal reflex also appears to be characterized by two temporal phases, the latter of which is dependent on de novo RNA and protein synthesis, cAMP, and MAPK signaling pathways (see, e.g., Alberini et al. 1995; Kandel 1997; Milner et al. 1998). Application of RNA or protein synthesis inhibitors to cocultured Aplysia sensory and motor neurons, for example, selectively blocks long-term facilitation (LTF) while leaving short-term facilitation (STF) intact (Montarolo et al. 1986). Similarly, a mutation in the nuclear phosphorylation site of PKA or inhibition of MAPK activity by anti-MAPK antibodies or PD098059 selectively interferes with LTF, while having no effect on STF (Kaang et al. 1993; Martin et al. 1997). Finally, stimulation that leads to LTF has been shown to be accompanied by translocation of both the catalytic subunit of PKA and MAPK to the sensory neuron nucleus where each of these pathways is thought to engage activators of transcription (Bacskai et al. 1993; Martin et al. 1997). These findings are in parallel to those of the LTP literature and suggest that the mechanisms underlying long-term synaptic plasticity are conserved across species and preparations.

A number of studies have suggested that the cAMP-response element binding protein (CREB) is the nuclear target where both PKA and MAPK exert their effects on LTF and LTP (see, e.g., Frank and Greenberg 1994; Stevens 1994; Yin and Tully 1996; Kandel 1997; Abel et al. 1998; Silva et al. 1998). CREB is a constituitively expressed nuclear transcription factor that consists of several functionally distinct isoforms (Kandel 1997; Abel et al. 1998; Silva et al. 1998). In Aplysia, for example, ApCREB1 appears to activate transcription by binding to CRE sites following phosphorylation by either PKA or calcium/calmodulin-dependent protein kinase (CaMK) (Dash et al. 1990; Kaang et al. 1993; Alberini et al. 1995). ApCREB2 contains a phosphorylation site for a MAPK (Gonzalez et al. 1991) and is thought to act as a repressor isoform (Abel et al. 1998). In support of this hypothesis, injection of oligonucleotides to CRE binding sites in to Aplysia sensory neurons effectively blocks LTF, while leaving STF intact (Dash et al. 1990). Conversely, injection of anti-ApCREB2 antibodies results in LTF ( $>1$ day) following stimulation that normally produces only STF ( $<1 \mathrm{hr}$ ) (Bartsch et al. 1995). Finally, recent studies have shown that stimuli that generate LTP in hippocampus promote
CRE-mediated gene transcription, an effect that is blocked by inhibitors of either PKA or MAPK (Impey et al. 1996, 1998a). Thus, CREB is a mechanism whereby intracellular signaling pathways may regulate the switch from short- to long-term plasticity and memory by acting to either promote or repress the synthesis of new proteins.

Consistent with the Aplysia model, a number of studies have implicated CREB in a variety of forms of learning and memory spanning a number of different species. Yin and colleagues (1994, 1995), for example, demonstrated that induced overexpression of a CREB activator isoform selectively enhanced the long-term retention of a classical conditioning task in Drosopbila. Conversely, induced expression of a dominant-negative (repressor) isoform blocked LTM (Yin et al. 1994, 1995). In the rat, injection of antisense oligonucleotides to CREB into hippocampus or amygdala has been shown to selectively affect LTM for spatial and taste aversion learning, respectively (Guzowski and McGaugh 1997; Lamprecht et al. 1997). Finally, transgenic mice lacking the $\alpha$ and $\delta$ isoforms of CREB have been shown to have impaired LTM, but not STM, on a variety of tasks, including social transmission of food preferences (Kogan et al. 1997) and spatial learning (Bourtchuladze et al. 1994). Consistent with the present results, CREB-deficient mice have also been shown to have impaired LTM, but not STM, for contextual and auditory fear conditioning (Bourtchuladze et al. 1994). Collectively, results strongly favor the hypothesis that CREB is a molecular switch underlying memory consolidation, including fear memory consolidation. Further, the findings of the present studies suggest that fear memory consolidation in the rat may involve convergence of PKA and MAPK onto nuclear targets such as CREB. Additional studies will be necessary to evaluate this hypothesis.

Where in the brain are Anisomycin, Rp-cAMPS, and PD098059 acting to disrupt the long-term plastic changes underlying fear memory consolidation? Although several regions are likely candidates, evidence would favor the hippocampus and the lateral (LA) and basal nuclei of the amygdala (see, e.g., Davis 1992; LeDoux 1992; Maren and Fanselow 1996). Lesions of the hippocampus, for example, have been shown to disrupt contextual fear conditioning, whereas those of the amygdala have been shown to disrupt both auditory and contextual fear (LeDoux et al. 1990a; Phillips and LeDoux 1992). It is generally assumed that the role

$$
\begin{array}{lllllllllllllll} 
& E & A & R & N & I & N & G & \begin{array}{l}
\boldsymbol{Q} \\
107
\end{array} & M & E & M & O & R & Y
\end{array}
$$


of hippocampus in fear conditioning is to provide the amygdala with a representation of the context in which conditioning occurs, and that the amygdala is the site of CS-US convergence or plasticity for both auditory and contextual fear conditioning (LeDoux 1992, 1995).

In support of the hypothesis that the amygdala is a key site of plasticity, the LA has been shown to receive convergent auditory and somatosensory inputs from the medial geniculate body, particularly from the medial division (MGm) and the posterior intralaminar nucleus (PIN) (LeDoux et al. 1984, 1985, 1990b; Romanski et al. 1993). The basal nucleus receives input from the hippocampus via the subiculum (Canteras and Swanson 1992). Importantly, LTP has been demonstrated in each of these pathways (Clugnet and LeDoux 1990; Maren and Fanselow 1995; Rogan and LeDoux 1995), and auditory fear conditioning has been shown to modify neural activity in the LA in the same manner that LTP does (Rogan et al. 1997; McKernan and Shinnick-Gallagher 1997). Thus, both the LA and the basal nucleus contain both the relevant inputs and the potential cellular mechanism whereby fear memory consolidation may occur. Alternatively, it may be the case that both the hippocampus and the amygdala undergo plastic changes necessary for contextual fear conditioning, whereas only the amygdala is necessary for tone conditioning (Phillips and LeDoux 1992). This interpretation would be consistent with studies demonstrating both synaptic plasticity and increases in the phosphorylation of MAPK, protein kinase C, and $\alpha$-CaMKII in the hippocampus following fear conditioning (Doyere et al. 1995; Atkins et al. 1998). It would also account for the relatively pronounced effects observed for contextual fear conditioning in the present studies because the drugs would have had multiple sites at which to act. Further experiments will be necessary to evaluate this hypothesis. Nonetheless, it is clear that the amygdala is one important site of CS-US convergence and plasticity. Consistent with this hypothesis, CRE-mediated gene transcription has recently been shown to increase in the amygdala following contextual fear conditioning (Impey et al. 1998b) and overexpression of CREB in the amygdala has been shown to facilitate long-term memory for fear-potentiated startle (S.A. Josselyn, W.A. Carlezon, C. Shi, R.L. Neve, E.J. Nestler, and M. Davis, unpubl.). Further, injection of Rp-cAMPS into the amygdala has been shown to attenuate fear-potentiated startle (C. Ding, Y.-L. Lee, and M. Davis, unpubl.).
Together with the LTP data, these studies suggest that molecular processes necessary for fear memory consolidation may be present in the amygdala. Additional studies employing selective cellular manipulations of this region will be necessary to further evaluate this hypothesis.

\section{Acknowledgments}

This research was supported in part by National Institute of Memtal Health grants RO1 MH 46516, KO2 MH00956, R37 MH 39774, and MH 11902-01A1. The work was also supported by a grant from the W.M. Keck Foundation to New York University. We thank Andrew Farnum for technical assistance. We also thank Hugh T. Blair, Yadin Dudai, Karim Nader, Marta Moita, and Marc Weisskopf for helpful comments about this manuscript.

The publication costs of this article were defrayed in part by payment of page charges. This article must therefore be hereby marked "advertisement" in accordance with 18 USC section 1734 solely to indicate this fact.

\section{References}

Abel, T., K.C. Martin, D. Bartsch, and E.R. Kandel. 1998. Memory suppressor genes: Inhibitory constraints on the storage of long-term memory. Science 279: 338-341.

Alberini, C.M., M. Ghirardi, Y. Huang, P.V. Nguyen, and E.R. Kandel. 1995. A molecular switch for the consolidation of long-term memory: cAMP-inducible gene expression. Ann. N.Y. Acad. Sci. 758: 261-286.

Alessi, D.R., A. Cuenda, P. Cohen, D.T. Dudley, and A.R. Saltiel. 1995. PD 098059 is a specific inhibitor of the activation of mitogen-activated protein kinase kinase in vitro and in vivo. J. Biol. Chem. 270: 27489-27494.

Atkins, C.M., J.C. Selcher, J.J. Petraitis, J.M. Trzaskos, and J.D. Sweatt. 1998. The MAP kinase cascade is required for mammalian associative learning. Nat. Neurosci. 1: 602-609.

Bacskai, B.J., B. Hochner, M. Mahaut-Smith, S.R. Adams, B.K. Kaang, E.R. Kandel, and R.Y. Tsien. 1993. Spatially resolved dynamics of CAMP and protein kinase A subunits in Aplysia sensory neurons. Science 260: 222-226.

Barnes, C.A., C.A. Erikson, S. Davis, and B.L. McNaughton. 1995. Hippocampal synaptic enhancement as a basis for learning and memory: A selected review of current evidence from behaving animals. In Brain and memory: Modulation and mediation of neuroplasticity (ed. J.L. McGaugh, N.M. Weinberger, and G.L. Lynch), pp. 259-276. Oxford University Press, New York, NY.

Bartsch, D., M. Ghirardi, P.A. Skehel, K.A. Karl, S.P. Herder, M. Chen, C.H. Bailey, and E.R. Kandel. 1995. Aplysia CREB2 represses long-term facilitation: Relief of repression converts transient facilitation into long-term functional and structural change. Cell 83: 979-992.

Bliss, T.V. and T. Lømo. 1973. Long-lasting potentiation of synaptic transmission in the dentate area of the anesthetized

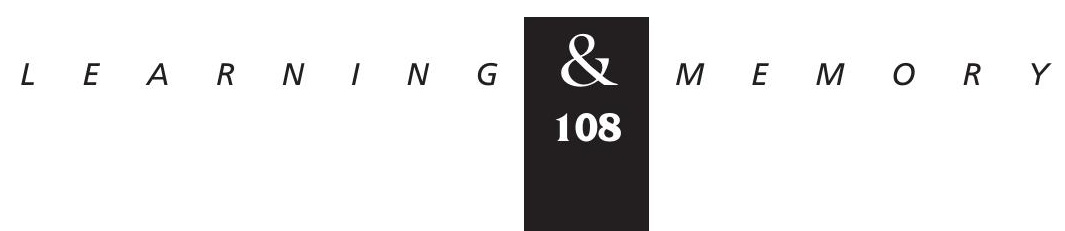


rabbit following stimulation of the perforant path. J. Physiol. (Lond.) 232: 331-356.

Bourtchuladze, R., B. Frenguelli, J. Blendy, D. Cioff, G. Schutz, and A.J. Silva. 1994. Deficient long-term memory in mice with a targeted mutation of the cAMP-responsive element-binding protein. Cell 79: 59-68.

Bourtchouladze, R., T. Abel, N. Berman, R. Gordon, K. Lapidus, and E.R. Kandel. 1998. Different training procedures recruit either one or two critical periods for contextual memory consolidation, each of which requires protein synthesis and PKA. Learn. \& Mem. 5: 365-374.

Bouton, M.E. and R.C. Bolles. 1980. Conditioned fear assessed by freezing and by the suppression of three different baselines. Anim. Learn. Behav. 8: 429-434.

Canteras, N.S. and L.W. Swanson. 1992. Projections of the ventral subiculum to the amygdala, septum, and hypothalamus: A PHAL anterograde tract-tracing study in the rat. J. Comp. Neurol. 324: 180-194.

Chapman, P.F., E.W. Kairiss, C.L. Keenan, and T.H. Brown. 1990. Long-term synaptic potentiation in the amygdala. Synapse 6: 271-278.

Clugnet, M. and J.E. LeDoux. 1990. Synaptic plasticity in fear conditioning circuits: Induction of LTP in the lateral nucleus of the amygdala by stimulation of the medial geniculate body. J. Neurosci. 10: 2818-2824.

Dash, P.K., B. Hochner, and E.R. Kandel. 1990. Injection of the cAMP-responsive element into the nucleus of Aplysia sensory neurons blocks long-term facilitation. Nature 345: 718-721.

Davis, M. 1992. The role of the amygdala in conditioned fear. In The amygdala: Neurobiological aspects of emotion, memory, and mental dysfunction (ed. J.P. Aggleton), pp. 255-306. Wiley-Liss, Inc., New York, NY.

Davis, H.P. and L.R. Squire. 1984. Protein synthesis and memory. Psychol. Bull. 96: 518-559.

Doyere, V., C. Redini-Del Negro, G. Dutrieux, G. Le Floch, S. Davis, and S. Laroche. 1995. Potentiation or depression of synaptic efficacy in the dentate gyrus is determined by the relationship between the conditioned and unconditioned stimulus in a classical conditioning paradigm in rats. Behav. Brain Res. 70: 15-29.

English, J.D. and J.D. Sweatt. 1997. A requirement for the mitogen-activated protein kinase cascade in hippocampal long-term potentiation. J. Biol. Chem. 272: 19103-19106.

Frey, U., Y.Y. Huang, and E.R. Kandel. 1993. Effects of cAMP stimulate a late stage of LTP in hippocampal CA1 neurons. Science 260: 1661-1664.

Frank, D.A. and M.E. Greenberg. 1994. CREB: A mediator of long-term memory from mollusks to mammals. Cell 79: 5-8.
Gonzalez, F.A., D.L. Raden, and R.J. Davis. 1991. Identification of substrate recognition determinants for human ERK1 and ERK2 protein kinases. J. Biol. Chem. 266: 22159-22163.

Guzowski, J.F. and J.L. McGaugh. 1997. Antisense oligodeoxynucleotide-mediated disruption of hippocampal cAMP response element binding protein levels impairs consolidation of memory for water maze training. Proc. Natl. Acad. Sci. 94: 2693-2698.

Huang, Y.Y. and E.R. Kandel. 1998. Postsynaptic induction and PKA-dependent expression of LTP in the lateral amygdala. Neuron 21: 169-178.

Huang, Y., X. Li, and E.R. Kandel. 1994. cAMP contributes to mossy fiber LTP initiating both a covalently mediated early phase and macromolecular synthesis-dependent phase late phase. Cell 79: 69-79.

Kaang, B.K., E.R. Kandel, and S.G.N. Grant. 1993. Activation of cAMP-responsive genes by stimuli that produce long-term facilitation in Aplysia sensory neurons. Neuron 10: 427-435.

Kandel, E.R. 1997. Genes, synapses, and long-term memory. J. Cell Physiol. 173: 124-125.

Kogan, J.H., P.W. Frankland, J.A. Blendy, J. Coblentz, Z. Marowitz, G. Schutz, and A.J. Silva. 1997. Spaced training induces normal long-term memory in CREB mutant mice. Curr. Biol. 7: 1-11.

Kornhauser, J.M. and M.E. Greenberg. 1997. A kinase to remember: Dual roles for MAP kinase in long-term memory. Neuron 18: 839-842.

Impey, S., M. Mark, E.C. Villacres, S. Poser, C. Chavkin, and D.R. Storm. 1996. Induction of CRE-mediated gene expression by stimuli that generate long-lasting LTP in area CA1 of the hippocampus. Neuron 16: 973-982.

Impey, S., K. Obrietan, S.T. Wong, S. Poser, S. Yano, G. Wayman, J.C. Deloulme, G. Chan, and D.R. Storm. 1998a. Cross talk between ERK and PKA is required for $\mathrm{Ca} 2+$ stimulation of CREB-dependent transcription and ERK nuclear translocation. Neuron 21: 869-883.

Impey, S., D.M. Smith, K. Obrietan, R. Donahue, C. Wade, and D.R. Storm. 1998b. Stimulation of cAMP response element (CRE)-mediated transcription during contextual learning. Nat. Neurosci. 1: 595-601.

Lamprecht, R., S. Hazvi, and Y. Dudai. 1997. cAMP response element-binding protein in the amygdala is required for longbut not short-term conditioned taste aversion memory. J. Neurosci. 17: 8443-8450.

LeDoux, J.E. 1992. Brain mechanisms of emotion and emotional learning. Curr. Opin. Neurobiol. 2: 191-197.

1995. Emotion: Clues from the brain. Annu. Rev. Psychol. 46: 209-235.

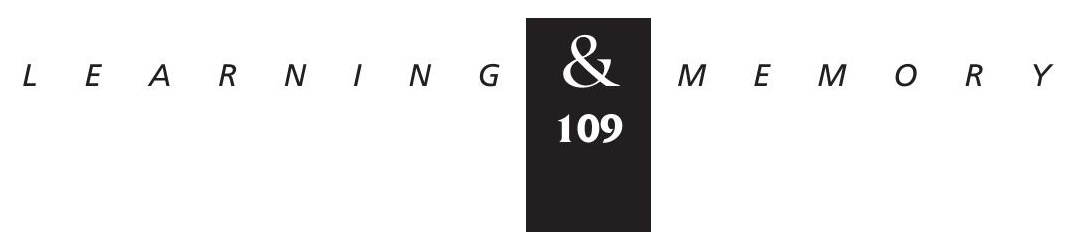




\section{Schafe et al.}

LeDoux, J.E., A. Sakaguchi, and D.J. Reis. 1984. Subcortical efferent projections of the medial geniculate nucleus mediate emotional responses conditioned by acoustic stimuli. J. Neurosci. 4: 683-698.

LeDoux, J.E., D.A. Ruggerio, and D.J. Reis. 1985. Projections to the subcortical forebrain from anatomically defined regions of the medial geniculate body in the rat. J. Comp. Neurol. 242: $182-213$.

LeDoux, J.E., L.M. Romanski, and A.E. Xagoraris. 1989. Indelibility of subcortical emotional memories. J. Cog. Neurosci. 1: 238-243.

LeDoux, J.E., P. Cicchetti, A. Xagorias, and L.M. Romanski. 1990a. The lateral amygdaloid nucleus: Sensory interface of the amygdala in fear conditioning. J. Neurosci.

10: 1062-1069.

LeDoux, J.E., C. Farb, and D.A. Ruggiero. 1990b. Topographic organization of neurons in acoustic thalamus that project to the amygdala. J. Neurosci. 10: 1043-1054.

Madison, D.V., R.C. Malenka, and R.A. Nicoll. 1991. Mechanisms underlying long-term potentiation of synaptic transmission. Annu. Rev. Neurosci. 14: 379-397.

Maren, S. and M.S. Fanselow. 1995. Synaptic plasticity in the basolateral amygdala induced by hippocampal formation stimulation in vivo. J. Neurosci. 15: 7548-7564.

- 1996. The amygdala and fear conditioning: Has the nut been cracked? Neuron 16: 237-240.

Martin, K.C., D. Michael, J.C. Rose, M. Barad, A. Casadio, H. Zhu, and E.R. Kandel. 1997. MAP kinase translocates into the nucleus of the presynaptic cell and is required for long-term facilitation in Aplysia. Neuron 18: 899-912.

McKernan, M.G. and P. Shinnick-Gallagher. 1997. Fear conditioning induces a lasting potentiation of synaptic currents in vitro. Nature 390: 607-611.

Meiri, N. and K. Rosenblum. 1998. Lateral ventricle injection of the protein synthesis inhibitor anisomycin impairs long-term memory in a spatial memory task. Brain Res. 789: $48-55$.

Milner, B., L.R. Squire, and E.R. Kandel. 1998. Cognitive neuroscience and the study of memory. Neuron 20: 445-468.

Miserendino, M.J.D., C.B. Sananes, K.R. Melia, and M. Davis. 1990. Blocking of acquisition but not expression of fear-potentiated startle by NMDA antagonists in the amygdala. Nature 345: 716-718.

Montarolo, P.G., P. Goelet, V.F. Castellucci, J. Morgan, E.R. Kandel, and S. Schacher. 1986. A critical period for macromolecular synthesis in long-term heterosynaptic facilitation in Aplysia. Science 234: 1249-1254.

Nguyen, P.V. and E.R. Kandel. 1996. A macromolecular synthesis-dependent late phase of long-term potentiation requiring CAMP in the medial perforant pathway of rat hippocampal slices. J. Neurosci. 16: 3189-3198.

Paxinos, G. and C. Watson. 1986. The rat brain in sterotaxic coordinates, 2nd ed. Academic Press, Orlando, FL.

Phillips, R. and J.E. LeDoux. 1992. Differential contribution of amygdala and hippocampus to cued and contextual fear conditioning. Behav. Neurosci. 106: 274-285.

Rogan, M.T. and J.E. LeDoux. 1995. LTP is accompanied by commensurate enhancement of auditory-evoked responses in a fear conditioning circuit. Neuron 15: 127-136.

Rogan, M.T., U.V. Staubli, and J.E. LeDoux. 1997. Fear conditioning induces associative long-term potentiation in the amygdala. Nature 390: 604-607.

Romanski, L.M., M. Clugnet, F. Bordi, and J.E. LeDoux. 1993. Somatosensory and auditory convergence in the lateral nucleus of the amygdala. Behav. Neurosci. 107: 444-450.

Rothermel, J.D. and L.H. Parker Botelho. 1988. A mechanistic and kinetic analysis of the interactions of the diastereoisomers of adenosine $3^{\prime}, 5^{\prime}$-(cyclic) phosphorothioate with purified cyclic AMP-dependent protein kinase. Biochem J. 251: 757-762.

Silva, A.J., J.H. Kogan, P.W. Frankland, and S. Kida. 1998. CREB and memory. Ann. Rev. Neurosci. 21: 127-148.

Stevens, C.F. 1994. CREB and memory consolidation. Neuron 13: $769-770$.

Yin, J.C. and T. Tully. 1996. CREB and the formation of long-term memory. Curr. Opin. Neurobiol. 6: 264-268.

Yin, J.C.P., J.S. Wallach, M. Del Vecchio, E.L. Wilder, H. Zhuo, W.G. Quinn, and T. Tully. 1994. Induction of a dominant negative CREB transgene specifically blocks long-term memory in Drosophila. Cell 79: 49-58.

Yin, J.C.P., M. Del Vecchio, H. Zhuo, and T. Tully. 1995. CREB as a memory modulator: Induced expression of a dCREB2 activator isoform enhances long-term memory in Drosophila. Cell 81: 107-115.

Received January 26, 1999; accepted in revised form March 4, 1999.

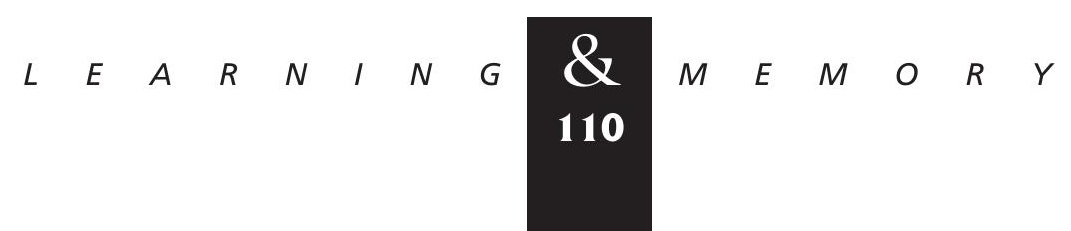




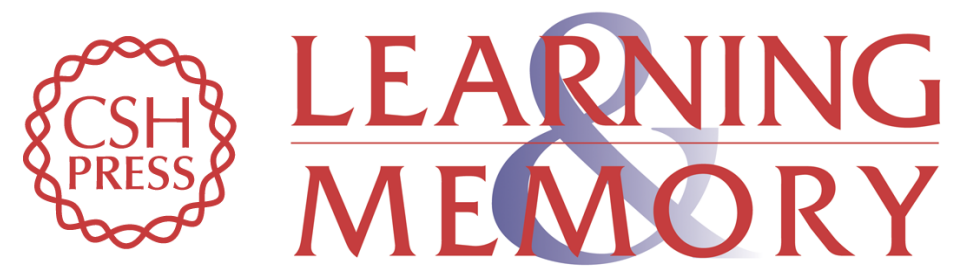

\section{Memory Consolidation for Contextual and Auditory Fear Conditioning Is Dependent on Protein Synthesis, PKA, and MAP Kinase}

Glenn E. Schafe, Nicole V. Nadel, Gregory M. Sullivan, et al.

Learn. Mem. 1999, 6:

Access the most recent version at doi:10.1101//m.6.2.97

References This article cites 58 articles, 17 of which can be accessed free at: http://learnmem.cshlp.org/content/6/2/97.full.html\#ref-list-1

License

Email Alerting Receive free email alerts when new articles cite this article - sign up in the box at the Service top right corner of the article or click here. 